Article

\title{
Screening of Crude Plant Extracts with Anti-Obesity Activity
}

\section{Changhyun Roh * and Uhee Jung *}

Radiation Research Division for Biotechnology, Advanced Radiation Technology Institute (ARTI), Korea Atomic Energy Research Institute (KAERI), 1266, Shinjeong-dong, Jeongeup, Jeonbuk 580-185, Korea

* Authors to whom correspondence should be addressed; E-Mails: chroh@kaeri.re.kr (C.R.); uhjung@kaeri.re.kr (U.J.); Tel.: +82-63-570-3227 (C.R.); Fax: +82-63-570-3229 (C.R.); Tel.: +82-63-570-3221 (U.J.); Fax: +82-63-570-3229 (U.J.).

Received: 15 November 2011; in revised form: 20 December 2011 / Accepted: 17 January 2012 / Published: 6 February 2012

\begin{abstract}
Obesity is a global health problem. It is also known to be a risk factor for the development of metabolic disorders, type 2 diabetes, systemic hypertension, cardiovascular disease, dyslipidemia, and atherosclerosis. In this study, we screened crude extracts from 400 plants to test their anti-obesity activity using porcine pancreatic lipase assay (PPL; triacylglycerol lipase, EC 3.1.1.3) in vitro activity. Among the 400 plants species examined, 44 extracts from plants, showed high anti-lipase activity using 2,4-dinitrophenylbutyrate as a substrate in porcine pancreatic lipase assay. Furthermore, 44 plant extracts were investigated for their inhibition of lipid accumulation in 3T3-L1 cells. Among these 44 extracts examined, crude extracts from 4 natural plant species were active. Salicis Radicis Cortex had the highest fat inhibitory activity, whereas Rubi Fructus, Corni Fructus, and Geranium nepalense exhibited fat inhibitory capacity higher than 30\% at $100 \mu \mathrm{g} / \mathrm{mL}$ in 3T3-L1 adipocytes, suggesting anti-obesity activity. These results suggest that four potent plant extracts might be of therapeutic interest with respect to the treatment of obesity.
\end{abstract}

Keywords: anti-obesity; plant extracts; screening; lipid inhibition 


\section{Introduction}

Obesity is a chronic metabolic disorder caused by an imbalance between energy intake and expenditure. Overweight and obesity are defined as abnormal or excessive fat accumulation that presents a risk to health [1-4]. Many scientific communities have become increasingly interested in the molecular regulation of triglyceride synthesis and in pharmaceutical approaches to reduce fat absorption and storage due to phytochemicals, presenting an exciting opportunity for the discovery of newer anti-obesity agents [5-7]. The regulation of fatty acid and triglyceride availability in biological responses depends on the activity of lipolytic enzymes present in fatty acid metabolism in adipose tissue [8-10].

The characterization and identification of several genes involved in lipid metabolism have yielded a rich pool of potential targets for drugs to treat obesity and other metabolic syndromes [11-14]. Pancreatic lipase, the main lipid digesting enzyme, removes fatty acids from the $\alpha$ and $\alpha^{\prime}$ positions of dietary triglycerides, which yield the lipolytic product $\beta$-monoglyceride and long chain saturated and polyunsaturated fatty acids. Inhibition of pancreatic lipase is an attractive targeted approach for the discovery of potent anti-obesity agents for obesity treatment $[15,16]$.

One of the screening strategies used in the discovery of anti-obesity drugs is to search for potent lipase inhibitors from plant extracts. Plants have been used as traditional natural medicines for healing many diseases. In particular, various oriental medicinal plants are reported to have biological activity [17]. In this study, we screened crude extracts from natural sources as potential anti-obesity agents by monitoring their anti-lipase activity. We also elucidated anti-obesity effects on lipid accumulation in cultured 3T3-L1 adipocytes by measuring Oil Red O staining and triglyceride (TG) contents as indicators of lipid accumulation. Among the plant extracts screened, the four most promising extracts (Rubi Fructus, Corni Fructus, Salicis Radicis Cortex, and Geranium nepalense) might be of therapeutic interest with respect to the treatment of obesity. To the best of our knowledge, these plant extracts have not been previously screened for their lipid inhibitory activity.

\section{Experimental Methods}

\subsection{Chemicals}

Four-hundred kinds of plants were purchased from a plant extract bank at Korea Research Institute of Bioscience \& Biotechnology (KRIBB), and were authenticated by H.K. Lee. A collection of voucher specimens is available for confirmation in the Plant Extract Bank, Korea Research Institute of Bioscience and Biotechnology, Daejeon, Republic of Korea. The plant extracts were dissolved in dimethylsulfoxide (DMSO) and used as samples for screening tests. Orlistat, p-nitrophenyl butyrate (NPB), and lipase (Type II: from Porcine pancreas) were purchased from Sigma-Aldrich Chemical Co. (St. Louis, MO, USA). All reagents were of the highest grade available.

\subsection{Preparation of Natural Extracts}

The plants were extracted three times with ethanol, and extracts were obtained through the removal of the solvent during evaporation. The concentrated samples were stored at $-20{ }^{\circ} \mathrm{C}$ for further study. 
Extracts were dissolved in DMSO at a final concentration that did not affect enzyme activity within the total volume $(1 \%)$.

\subsection{Pancreatic Lipase Inhibition Assay}

Porcine pancreatic lipase (PPL, type II) activity was measured using p-nitrophenyl butyrate ( $p$-NPB) as a substrate. The method used for measuring the pancreatic lipase activity was modified from that previously described by Kim, et al. and Zheng, et al. [18,19]. PPL stock solutions $(1 \mathrm{mg} / \mathrm{mL})$ were prepared in a $0.1 \mathrm{mM}$ potassium phosphate buffer $(\mathrm{pH} 6.0)$ and the solutions were stored at $-20{ }^{\circ} \mathrm{C}$. To determine the lipase inhibitory activity, the extracts (final concentrations 100, 50, 25, 10, 5, 2.5, $1.25 \mu \mathrm{g} / \mathrm{mL}$ ) or Orlistat (at same concentrations) as a positive control were pre-incubated with PPL for $1 \mathrm{~h}$ in a potassium phosphate buffer $(0.1 \mathrm{mM}, \mathrm{pH} 7.2,0.1 \%$ Tween 80$)$ at $30^{\circ} \mathrm{C}$ before assaying the PPL activity. The reaction was then started by adding $0.1 \mu \mathrm{L}$ NPB as a substrate, all in a final volume of $100 \mu \mathrm{L}$. After incubation at $30^{\circ} \mathrm{C}$ for $5 \mathrm{~min}$, the amount of $p$-nitrophenol released in the reaction was measured at $405 \mathrm{~nm}$ using a UV-Visible spectrophotometer (BioTek Synergy HT, Winooski, VT, USA). The activity of the negative control was also examined with and without an inhibitor. The inhibitory activity (I) was calculated according to the following formula:

$$
\text { Inhibitory activity }(\mathrm{I} \%)=100-((\mathrm{B}-\mathrm{b}) /(\mathrm{A}-\mathrm{a}) \times 100)
$$

where $\mathrm{A}$ is the activity without inhibitor; $\mathrm{a}$ is the negative control without inhibitor; $\mathrm{B}$ is the activity with inhibitor; and $\mathrm{b}$ is the negative control with inhibitor. DMSO was used as negative control and its activity was also examined.

\subsection{Cell Culture and Differentiation}

3T3-L1 preadipocytes were obtained from ATCC (Manassas, VA, USA). 3T3-L1 preadipocytes were grown in DMEM supplemented with $10 \%(\mathrm{v} / \mathrm{v})$ heat-inactivated FBS at $37{ }^{\circ} \mathrm{C}$ in an atmosphere containing 5\% $\mathrm{CO}_{2}$. To induce adipocyte differentiation, 2-day post-confluent 3T3-L1 preadipocytes (day 0 ) were stimulated for $48 \mathrm{~h}$ (day 2) with an inducer $(10 \mu \mathrm{g} / \mathrm{mL}$ insulin, $2.5 \mu \mathrm{M}$ dexamethasone, and $0.5 \mathrm{mM} 3$-isobutyl-1-methylxanthine) including natural extracts, and then maintained for 6 days (day 8) in DMEM supplemented with $10 \%$ FBS and $10 \mu \mathrm{g} / \mathrm{mL}$ insulin including natural extracts. 3T3-L1 cells were treated with natural extracts in DMEM supplemented with 10\% FBS for 2 days (day 10). To examine the effect of natural extracts on adipocyte differentiation in 3T3-L1 cells, the media and natural extracts were changed every 2 days until the end of the experiment at day 10 .

\subsection{Cell Viability and Oil Red O Staining Intracellular Triglycerides}

Cell viability was determined colorimetrically using an MTT assay [20]. Cells cultured in DMEM medium were treated with natural extracts at a final concentration of $100 \mu \mathrm{g} / \mathrm{mL}$ for 2 days, and then incubated with a $5 \mathrm{mg} / \mathrm{mL}$ MTT (3-(4,5-dimetyl-2-thiazolyl)-2,5-diphenyltetrazoliumbromide) solution (Sigma) for $3 \mathrm{~h}$. After the cells were dissolved in $0.04 \mathrm{~N} \mathrm{HCl}$ (in isopropanol), the formazane level was analyzed by measuring the optical density (OD) at $570 \mathrm{~nm}$ (against OD at $630 \mathrm{~nm}$ ) [18]. 3T3-L1 adipocytes were washed with PBS and fixed with 10\% formalin for $30 \mathrm{~min}$. After two washes with distilled water, the cells were stained for at least $1 \mathrm{~h}$ at room temperature in a freshly diluted Oil Red $\mathrm{O}$ 
solution (Oil Red O stock solution used is $0.5 \%$ Oil Red O in isopropanol). Finally, the dye retained in the 3T3-L1 cells was eluted with isopropanol and quantified by measuring the absorbance at $500 \mathrm{~nm}$.

\subsection{Measurement of Triglyceride (TG) and Glycerol}

Cellular TG contents were measured using a commercial TG assay kit (Asan Pharm. Co., Seoul, Republic of Korea) according to the manufacturer's instructions. Cells were treated with plant extracts at concentrations of $100 \mu \mathrm{g} / \mathrm{mL}$ in 6-well plates during adipocyte differentiation for 6 days. The cells were washed twice with phosphate-buffered saline (PBS), scraped in $75 \mu \mathrm{L}$ of a homogenizing

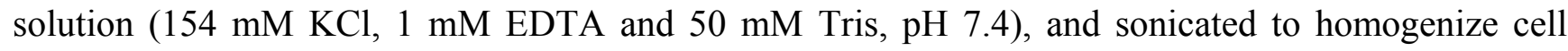
suspension. The residual cell lysate was centrifuged at $3000 \times \mathrm{g}$ for $5 \mathrm{~min}$ at $25^{\circ} \mathrm{C}$ to remove fat layers. The supernatants were assayed for TG and protein contents. TG was normalized to the protein concentration determined by the Bradford assay using bovine serum albumin (BSA) as standard. The results were expressed in milligrams of TG per milligram of cellular protein. Lipolysis was assessed through the measurement of glycerol released (Free glycerol reagent, Sigma, St. Louis, MO, USA) into the medium, according to the manufacturer's instructions [21]. Briefly, differentiated 3T3-L1 adipocytes were treated with plant extracts for $24 \mathrm{~h}$. After incubation, $50 \mu \mathrm{L}$ of the medium was incubated with $200 \mu \mathrm{L}$ of a Free Glycerol Reagent for $15 \mathrm{~min}$ at room temperature. The glycerol was quantified by measuring absorbance at $540 \mathrm{~nm}$.

\subsection{Statistics}

Statistical analysis was done by using one way analysis of variance using the SPSS program [22]. Values of $p<0.05$ were considered to be statistically significant.

\section{Results and Discussion}

\subsection{Anti-Lipase Activity of Crude Natural Source Extracts}

Four-hundred crude extracts were prepared from natural plant species found in Korea or Asia and their anti-lipase activity was investigated at a concentration of $100 \mu \mathrm{g} / \mathrm{mL}$ for PPL inhibition. The inhibitory activities towards pancreatic lipase are reported in Table 1. Among the 400 plant extracts examined, 44 crude extracts from natural plant species, at a concentration of $100 \mu \mathrm{g} / \mathrm{mL}$, significantly inhibited PPL in vitro activity when using a 2,4-dinitrophenylbutirate-based assay. Among those examined, four of the extracts showed a relatively high anti-lipase activity of more than $30 \%$. The significant inhibition of PPL was observed up to $32.5 \%$ with Rubi Fructus fruit, 34.8\% with Corni Fructus fruit, 38\% with Salicis Radicis Cortex bark and 31.4\% with Geranium nepalense whole grass, respectively. Treatment with Orlistat (at final concentration $100 \mu \mathrm{g} / \mathrm{mL}$ ) as a positive control, a well-known anti-lipase agent, significantly inhibited the PPL activity up to $42 \%$. Orlistat, a hydrogenated derivative of lipstatin, is the only pancreatic lipase inhibitor currently approved for a long-term treatment of obesity. Crude extracts of Rubi Fructus, Corni Fructus, Salicis Radicis Cortex, and Geranium nepalense were further investigated for their PPL inhibitory effects at different concentrations, and a dose-response curve was obtained, as shown in Figure 1. 
Table 1. Forty four plant extracts that inhibit porcine pancreatic lipase (PPL).

\begin{tabular}{|c|c|c|c|c|c|}
\hline No. & Latin Name & Scientific Name & Family Name & $\begin{array}{c}\text { Plant } \\
\text { Part }\end{array}$ & $\begin{array}{c}\text { Inhibition } \\
(\%) *\end{array}$ \\
\hline 1 & Platycodi Radix & Platycodon grandiflorum A. De Candolle & Campanulaceae & Root & $3.5 \pm 0.7$ \\
\hline 2 & Aconiti Tuber & Aconitum carmichaeli Debeaux & Ranunculaceae & Root & $12.1 \pm 1.1$ \\
\hline 3 & Cannabis Semen & Cannabis sativa Linne & Moraceae & Seed & $7.7 \pm 0.2$ \\
\hline 4 & Chaenomelis Fructus & Chaenomeles sinensis (Thouin) Koehne & Rosaceae & Fruit & $7.1 \pm 0.7$ \\
\hline 5 & Actinidiae Fructus & Actinidia chinensis & Actinidiaceae & Fruit & $3.2 \pm 0.2$ \\
\hline 6 & Tribuli Semen & Tribulus terrestris & Zygophyllaceae & Seed & $2.5 \pm 0.6$ \\
\hline 7 & Lilie Bulbus & Lilium brownii var. viridulun Baker & Liliaceae & Stem & $6.5 \pm 1.2$ \\
\hline 8 & Luffae Fructus Retinervus & Luffa cylindrica Roemer & Cucurbitaceae & Fruit & $8.2 \pm 1.4$ \\
\hline 9 & Crataegi Fructus & Crataegus pinnatifida Bunge var. typica Schneider & Rosaceae & Fruit & $5.5 \pm 1.2$ \\
\hline 10 & Puerariae Radix & Pueraria thunbergiana Bentham & Leguminosae & Root & $3.2 \pm 0.1$ \\
\hline 11 & Nardostachyos Rhizoma & Nardostachys chinensis Batal & Valerianaceae & Rhizoma & $6.4 \pm 0.5$ \\
\hline 12 & Zizyphi Fructus & Zizyphus jujuba Miller var. inermis Rehder & Rhamnaceae & Fruit & $6.6 \pm 1.5$ \\
\hline 13 & Akebiae Caulis & Akebia quinata Decaisne & Lardizabalaceae & Stem & $11.5 \pm 0.1$ \\
\hline 14 & Quisqalis Fructus & Quisqualis indica Linné & Combretaceae & Fruit & $11.8 \pm 0.3$ \\
\hline 15 & Loranthi Ramulus & Loranthus parasticus Merr. & Loranthaceae & $\begin{array}{l}\text { Whole } \\
\text { grass }\end{array}$ & $13.5 \pm 0.7$ \\
\hline 16 & Schizandrae Fructus & Schizandra chinensis Baillon & Schizandraceae & Fruit & $5.8 \pm 0.2$ \\
\hline 17 & Lonicerae Folium & Lonicera japonica Thunberg & Caprifoliaceae & Stem & $6.4 \pm 0.5$ \\
\hline 18 & Rehmaniae Radix Preparata & Rehmannia glutinosa & Scrophulariaceae & Root & $6.8 \pm 1.1$ \\
\hline 19 & Dipsaci Radix & Dipsacus asperoides C. Y. Cheng et T. M. Ai & Dipsacaceae & Root & $12.5 \pm 0.3$ \\
\hline 20 & Morindae Radix & Morinda officinalis How & Rubiaceae & Root & $3.9 \pm 0.7$ \\
\hline 21 & Perillae Semen & Perilla sikokiana Nakai & Labiatae & Seed & $8.4 \pm 0.3$ \\
\hline 22 & Pruni Nakaii Semen & Prunus nakaii Leveille & Rosaceae & Seed & $7.7 \pm 0.6$ \\
\hline 23 & Meliae Fructus & Melia azedarach Linné var. japonica Makino & Meliaceae & Fruit & $8.6 \pm 0.8$ \\
\hline 24 & Bletillae Rhizoma & Bletilla striata (Thunberg) Reichenbach fil. & Orchidaceae & Rhizoma & $12.1 \pm 0.4$ \\
\hline 25 & Hedyotidis Diffusae Herba & Oldenlandia diffusa (Willd.) Roxburgh & Rubiaceae & $\begin{array}{l}\text { Whole } \\
\text { grass }\end{array}$ & $1.80 \pm 0.4$ \\
\hline 26 & Hoelen rubra & Poria cocos wolf & Polyporaceae & Bark & $12.7 \pm 0.5$ \\
\hline 27 & Gastrodiae Rhizoma & Gastrodia Blume & Orochidaceae & Rhizoma & $8.4 \pm 0.8$ \\
\hline 28 & Gentianae Scabrae Radix & Gentiana scabra & Sympetalae & Root & $7.5 \pm 1.1$ \\
\hline 29 & Cuscutae Semen crudus & Cuscuta chinensis Lamark & Convolvulaceae & Seed & $5.8 \pm 0.4$ \\
\hline 30 & Tetrapanacis Medulla & Tetrapanax papyriferus K. Koch & Araliaceae & Stem & $6.6 \pm 0.7$ \\
\hline 31 & Fritillariae Bulbus & Fritillaria thunbergii Miquel & Liliaceae & Stem & $8.7 \pm 0.5$ \\
\hline 32 & Patriniae Radix & Patrinia villosa Jussieu & Valerianaceae & Root & $7.7 \pm 1.4$ \\
\hline 33 & Scutellariae Radix & Scutellaria baicalenis Georgi & Labiatae & Root & $8.7 \pm 0.4$ \\
\hline 34 & Astragali Radix & Astragalus membranaceus Bunge & Leguminosae & Root & $7.4 \pm 1.4$ \\
\hline 35 & Phellodendri Cortex & Phellodendron amurense Ruprecht & Rutaceae & Bark & $11.5 \pm 0.2$ \\
\hline 36 & Drynariae Rhizoma & Drynaria fortunei Smith. & Polypodiaceae & Rhizoma & $10.5 \pm 0.4$ \\
\hline 37 & Rubi Fructus & Rubus coreanus Miquel & Rosaceae & Fruit & $32.5 \pm 1.1$ \\
\hline 38 & Eriobotriae Folium & Eriobotrya japonica Lindley & Rosaceae & Leaf & $9.8 \pm 0.3$ \\
\hline 39 & Corni Fructus & Cornus officinalis Siebold et Zuccarini & Cornaceae & Fruit & $34.8 \pm 2.3$ \\
\hline 40 & Forsythiae Fructus & Forsythia koreana Nakai & Oleaceae & Fruit & $5.7 \pm 1.2$ \\
\hline 41 & Salicis Radicis Cortex & Ulmus darvidian for. Suberose & Ulmaceae & Bark & $38.0 \pm 1.9$ \\
\hline
\end{tabular}


Table 1. Cont.

\begin{tabular}{|c|c|c|c|c|c|}
\hline No. & Latin Name & Scientific Name & Family Name & Plant Part & $\begin{array}{c}\text { Inhibition } \\
(\%) *\end{array}$ \\
\hline 42 & Ammomi Tsao-ko Frucuts & Amomum tsao-ko Crevost et Lemaire & Zingiberaceae & Fruit & $7.5 \pm 0.6$ \\
\hline 43 & Polygoni Avicularis Herba & Polygonum aviculare Linné & Polygonaceae & Whole grass & $21.2 \pm 1.7$ \\
\hline 44 & Geranium Nepalense & Geranium thunbergii Siebold et Zuccarini & Geraniaceae & Whole grass & $31.4 \pm 0.7$ \\
\hline 45 & Orlistat & & & & $42.0 \pm 2.5$ \\
\hline
\end{tabular}

* The inhibition of lipase activity by crude natural extracts was compared to the one observed with the positive control (Orlistat). Data are presented as average \pm standard deviation $(n=3)$ and the anti-lipase activity was investigated at a concentration of $100 \mu \mathrm{g} / \mathrm{mL}$ for PPL inhibition.

Figure 1. Porcine pancreatic lipase (PPL) inhibitory activities of Rubi Fructus, Corni Fructus, Salicis Radicis Cortex, Geranium nepalense. Orlistat was used as a positive control. Experiments have been performed in triplicate.

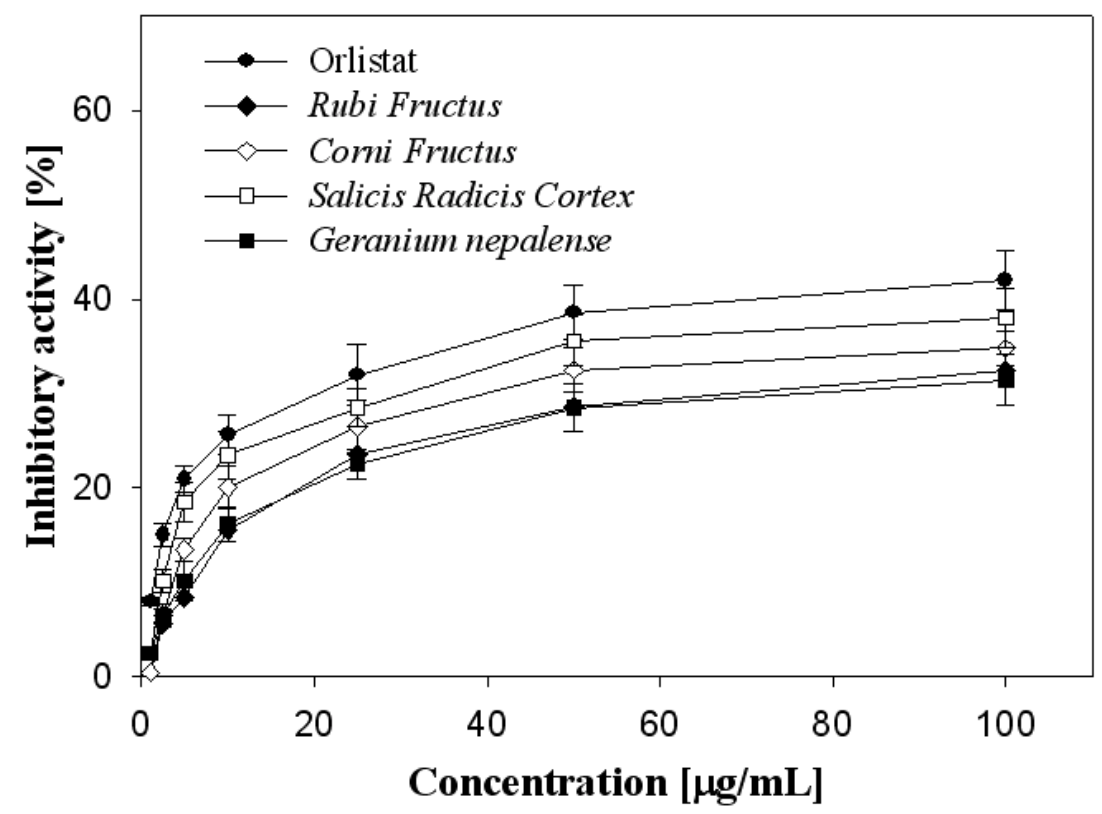

\subsection{Effect of Cell Viability and Lipid Inhibition in 3T3-L1 Cells}

The 3T3-L1 adipocytes were cultured and differentiated in a Dulbecco Modified Eagle Medium containing 10\% fetal bovine serum for 6 to 8 days in the absence and presence of 44 plant extracts (at a final concentration, $100 \mu \mathrm{g} / \mathrm{mL}$ ) according to differentiating protocols. Extracts were dissolved in DMSO at a final concentration that did not affect cell activity within the total volume (1\%). As shown in Figure 2, the 44 plant extracts at $100 \mu \mathrm{g} / \mathrm{mL}$ attenuated lipid accumulation in differentiated adipocytes as evidenced by Oil Red O staining. Among the natural extracts examined, the four potent natural extracts (Rubi Fructus, Corni Fructus, Salicis Radicis Cortex, and Geranium nepalense) were found to significantly reduce lipid accumulation in 3T3-L1 adipocytes, suggesting anti-obesity activity. In Figure $2 \mathrm{~A}, \mathrm{~B}$, the effects of plant extracts on fat droplet formation in 3T3-L1 cells, and inhibition through the quantification method of Oil Red O staining, were presented. To examine the effect of plant extracts on cell viability of 3T3-L1 preadipocytes, we performed an MTT assay, which assesses cell viability by measuring mitochondrial activity in 3T3-L1 cells treated with concentrations of crude 
extracts. The potent crude extracts (Rubi Fructus, Corni Fructus, Salicis Radicis Cortex, and Geranium nepalense) screened have relatively low cytotoxicity to 3T3-L1 preadipocyte cells. The cell cytotoxicity remained approximately $90-100 \%$ (data not shown).

Figure 2. Effects of plant extracts on Oil Red O staining in cultured 3T3-L1 adipocytes. (A) Effects of plant extracts on fat droplet formation in 3T3-L1 cells. It was stained with Oil Red O dye and examined using a light microscope; (B) Relative lipid content by quantification method of Oil Red O staining. Data are presented as average $\pm \operatorname{SD}(n=3)$. * indicates $p<0.05$.

(A)

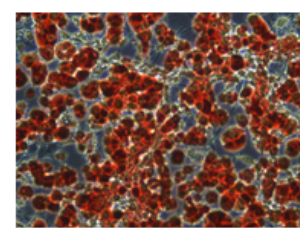

Control

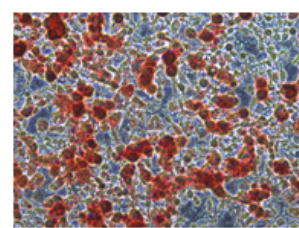

Rubi Fructus

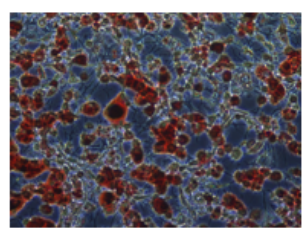

Corni Fructus

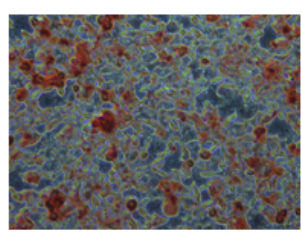

Salicis Radicis Cortex Geranium nepalense

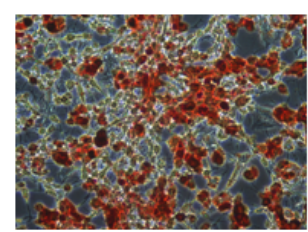

(B)

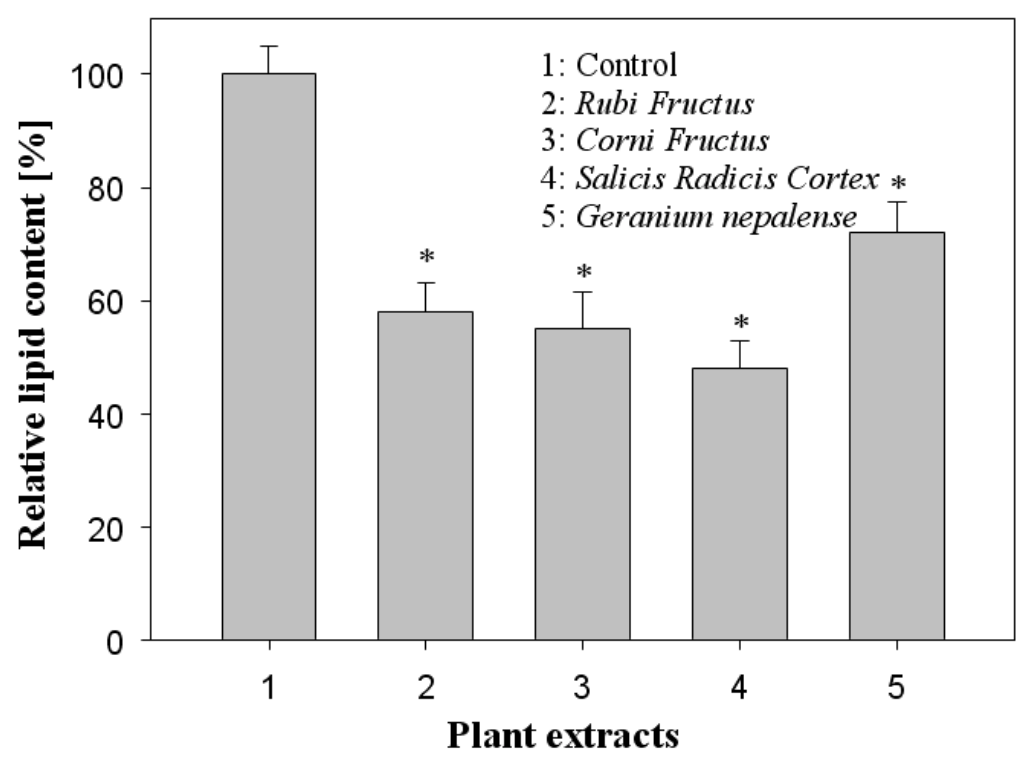

As shown in Figure 3A, lipid accumulation was measured based on the TG contents of 3T3-L1 cells differentiated in the presence of natural extracts. Furthermore, the lipolysis was assessed through the measurement of glycerol released in culture medium for $24 \mathrm{~h}$ incubation, as shown in Figure 3B. The four natural extracts that exhibited inhibitory activity towards pancreatic lipase (Rubi Fructus, Corni Fructus, Salicis Radicis Cortex, and Geranium nepalense) were found to inhibit triglyceride accumulation in 3T3-L1 adipocytes and trigger lipid metabolism process to glycerol release.

Rubi Fructus, the unripe fruit of Rubus Chingii $\mathrm{Hu}$ belonging to the Rosaceae family, can be found in many parts of the Asia, especially in China. In general, Rubi Fructus has estrogenic effect, promote lymphocyte proliferation and elevate testosterone level by promoting the activity of steroid synthesizing enzymes and by inhibiting their degradation [23]. Corni Fructus, the pulp of Cornus officinalis sieb. belonging to the Cornaceae in family, can be found in China, Japan and Korea. The biological activity of Corni Fructus was reported to relieve cyclophosphamid-induced leukopenia 
and to have antibacterial effects [24]. Salicis Radicis Cortex belonging to the Ulmaceae in family was reported to have antioxidant, antitumor, antimetastatic effects [25], to increase NO synthase activity [26], to lower LDL cholesterol levels [27], to prevent cancer development and metastasis [28] and to be effective in wound healing, angiogenesis, and cardiovascular disease [29]. Geranium Nepalense belonging to the Geraniaceae in family was reported to have antibacterial and antifungal effects [30]. Even though these four plants have reported to have various biological activities, there was no report indicating them to have lipid inhibitory activity.

Figure 3. Effects of plant extracts on adipocyte differentiation in 3T3-L1 cells. (A) Triglyceride (TG) accumulation was measured by TG contents of 3T3-L1 cells differentiated in the presence of natural extracts; (B) Lipolysis was assessed by the measurement of glycerol released into the medium. Data are presented as average $\pm \operatorname{SD}(n=3)$. * indicates $p<0.05$.

(A)

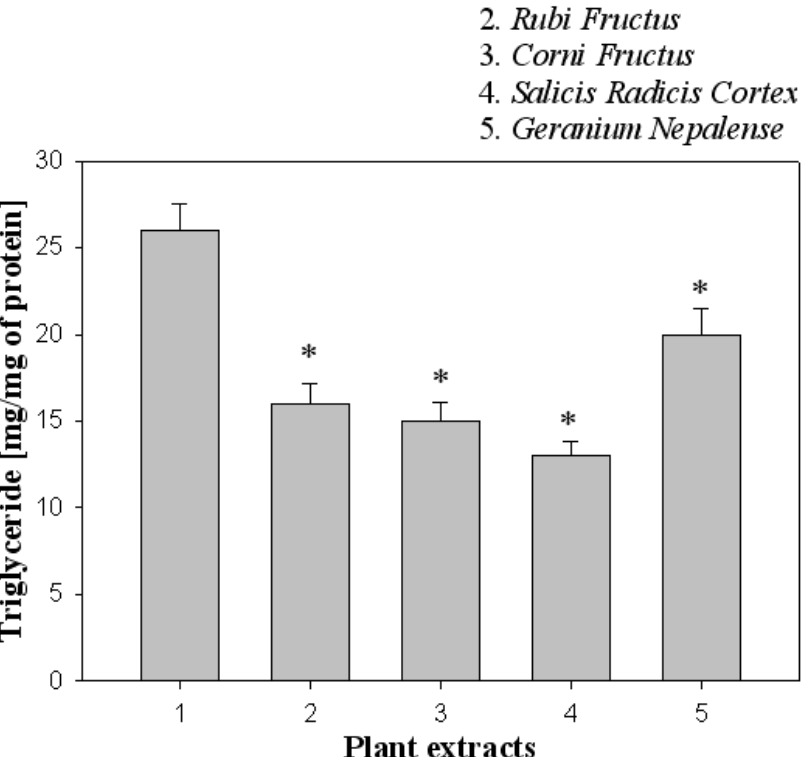

(B)

1. Control

2. Rubi Fructus

3. Corni Fructus

4. Salicis Radicis Cortex

5. Geranium Nepalense

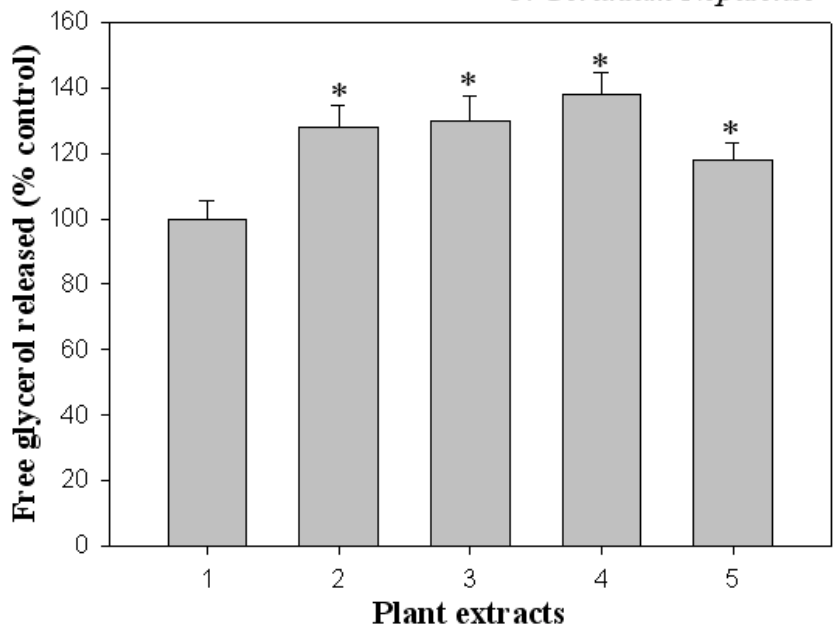

\section{Conclusions}

Obesity is a risk factor for metabolic syndromes, and a flexible approach for the treatment of obesity is to promote early adipogenesis in adipose tissue, thereby leading to the replacement of enlarged adipocytes that secrete inflammatory factors with small adipocytes. In this study, we screened crude anti-obesity drugs from four-hundred plant extracts on in vitro enzymatic lipase activity. Among 400 plant extracts examined, 44 extracts from plant extracts significantly inhibited against in vitro anti-lipase activity. Among 44 natural extracts examined, the four plant extracts were active to inhibit lipid formation in 3T3-L1 adipocytes, suggesting their use as crude anti-obesity agents. Among them, Salicis Radicis Cortex had highest fat inhibition activity. Therefore, these results suggest that these four active plant extracts could be useful for prevention or treatment of obesity. 


\section{Acknowledgments}

This work was supported by grant No. 2007-2000091 from Nuclear R \& D Program of Ministry of Education, Science and Technology, Republic of Korea.

\section{References}

1. Spiegelman, B.M.; Flier, J.S. Obesity and the regulation of energy balance. Cell 2001, 104, 531-543.

2. Kopelman, P.G. Obesity as a medical problem. Nature 2000, 404, 635-643.

3. Panico, S.; Lannuzzi A. Dietary fat composition and the metabolic syndrome. Eur. J. Lipid Sci. Technol. 2004, 106, 61-67.

4. Wakil, S.J.; Abu-Elheiga, L.A. Fatty acid metabolism: Target for metabolic syndrome. J. Lipid Res. 2009, S139-S143.

5. Bray, G.A.; Tartaglia, L.A. Medicinal strategies in the treatment of obesity. Nature 2000, 404, 672-677.

6. Sharma, N.; Sharma, V.K.; Seo, S.Y. Screening of some medicinal plants for anti-lipase activity. J. Ethnopharmacol. 2005, 97, 453-456.

7. Hino, K.; Nagata, H.; Shimonishi, M.; Ido, M. High-throughput screening for small-molecule adiponectin secretion modulators. J. Biomol. Screen.2011, 16, 628-636.

8. Vázquez-Vela, M.E.F.; Torres, N.; Tovar, A.R. White adipose tissue as endocrine organ and its role in obesity. Arch. Med. Res. 2008, 39, 715-728.

9. Tanzi, M.C.; Fare, S. Adipose tissue engineering: State of the art, recent advances and innovative approaches. Expert Rev. Med. Devices 2009, 6, 533-551.

10. Miyoshi, H.; Perfield, J.W., II; Obin, M.S.; Greenberg A.S. Adipose triglyceride lipase regulates basal lipolysis and lipid droplet size in adipocytes. J. Cell. Biochem. 2008, 105, 1430-1436.

11. Shi, Y.; Burn, P. Lipid metabolism enzymes: Emerging drug targets for the treatment of obesity. Nat. Rev. Drug Discov. 2004, 3, 695-710.

12. Hong, Y.H.; Hishikawa, D.; Miyahara, H.; Tsuzuki, H.; Nishimura, Y.; Gotoh, C.; Choi, K.C.; Hokari, Y.; Takagi, Y.; Lee, H.G.; et al. Up-regulation of adipogenin, an adipocyte plasma transmembrane protein, during adipogenesis. Mol. Cell. Biochem. 2005, 276, 133-141.

13. Reilly, S.M.; Lee, C.H. PPAR $\delta$ as a therapeutic target in metabolic disease. FEBS Lett. 2008, 582, 26-31.

14. Kos, K.; Wilding, J.P.H. SPARC: A key player in the pathologies associated with obesity and diabetes. Nat. Rev. Endocrinol. 2010, 6, 225-235.

15. Thomson, A.B.; de Pover, A.; Keelan, M.; Jarocka-Cyrta, E.; Clandinin, M.T. Inhibition of lipid absorption as an approach to the treatment of obesity. Meth. Enzymol. 1997, 286, 3-41.

16. Tsujita, T.; Ninomiya, H.; Okuda, H. p-Nitrophenyl butyrate hydrolyzing activity of hormone-sensitive lipase from bovine adipose tissue. J. Lipid Res. 1989, 30, 997-1004.

17. Shizhen, L.; Xiwen, L. Compendium of Materia Medica; Foreign Languages Press: Beijing, China, 2003; Volume 6. 
18. Kim, Y.S.; Lee, Y.M.; Kim, H.; Kim, J.; Jang, D.K.; Kim, J.H.; Kim, J.S. Anti-obesity effect of Morus bombycis root extract: Anti-lipase activity and lipolytic effect. J. Ethnopharmacol. 2010, 130, 621-624.

19. Zheng, C.D.; Duan, Y.Q.; Gao, J.M.; Ruan, Z.G. Screening of anti-lipase properties of 37 traditional Chinese medicinal herbs. J. Chin. Med. Assoc. 2010, 73, 319-324.

20. Yang, Z.; Tu, Y.; Xia, H.; Jie, G.; Chen, X.; He, P. Suppression of free-radicals and protection against $\mathrm{H} 2 \mathrm{O} 2$-induced oxidative damage in HPF-1 cell by oxidized phenolic compounds present in black tea. Food Chem. 2007, 105, 1349-1356.

21. Mcgowan, M.W.; Artiss, J.D.; Strandbergh, D.R.; Zak, B. A peroxidase-coupled method for the colorimetric determination of serum triglycerides. Clin. Chem. 1983, 29, 538-542.

22. SPSS, version 19.0; IBM: Chicago, IL, USA, 2010.

23. Kim, J.S.; Jeon, W.J.; You, H.J.; Park, M.S.; Ji, G.E. Inhibitory activities of Rubi fructus on digestive enzymes. Food Sci. Biotechnol. 2010, 19, 1165-1170.

24. Park, C.H.; Cho, E.J.; Yokozawa, T. Protection against hypercholesterolemia by Corni fructus extract and its related protective mechanism. J. Med. Food 2009, 12, 973-981.

25. Bonfili, L.; Cecarini, V.; Amici, M.; Cuccioloni, M.; Angeletti, M.; Keller, J.N.; Eleuteri, A.M. Natural polyphenols as proteasome modulators and their role as anti-cancer compounds. FEBS $J$. 2008, 275, 5512-5526.

26. Tunon, M.J.; Garcia-Mediavilla, M.V.; Sanchez-Campos, S.; Gonzalez-Gallego, J. Potential of flavonoids as antiinflammatory agents: Modulation of pro-inflammatory gene expression and signal transduction pathways. Curr. Drug Metab. 2009, 10, 256-271.

27. Lugasi, A. Foods fortified with phytosterins: Their role in decreasing serum cholesterol level, their European Community authorization and requirements for placing them on the market. Orv. Hetil. 2009, 150, 483-496.

28. Ovesna, Z.; Vachalkova, A.; Horvathova, K. Taraxasterol and beta-sitosterol: New naturally compounds with chemoprotective/chemopreventive effects. Neoplasma 2004, 51, 407-414.

29. Plat, J.; Mensink, R.P. Effects of plant sterols and stanols on lipid metabolism and cardiovascular risk. Nutr. Metab. Cardiovasc. Dis. 2001, 11, 31-40.

30. Uprety, Y.; Asselin, H.; Boon, E.K.; Yadav, S.; Shrestha, K.K. Indigenous use and bio-efficacy of medicinal plants in the Rasuwa District, Central Nepal. J. Ethnobiol. Ethnomed. 2010, 6, 3-9.

(C) 2012 by the authors; licensee MDPI, Basel, Switzerland. This article is an open access article distributed under the terms and conditions of the Creative Commons Attribution license (http://creativecommons.org/licenses/by/3.0/). 